\title{
Saga rooted in conflict between men and nature
}

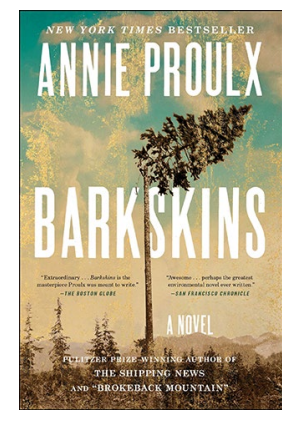

\author{
Barkskins: A Novel
}

By Annie Proulx

SCRIBNER: 2016. 736 PP. $€ 19$ follow a tale that traces the bloodlines of these two men, intersecting with and generating a violent saga of cultural and environmental eradication.

Spanning over 700 pages and 300 years, Barkskins is self-evidently a novel of conflict. With the characters treated as more or less disposable, they draw less focus than the larger themes at play: the struggle between traditional and new, between necessity and greed, and between men and the real protagonist of the novel - nature itself. Proulx uses her extensive knowledge of shipping, logging, and cutting to inform the reader of the ways in which despoliation of land occurs, and as a caution to recognize nature and its trees not as a perpetual constant, but rather as a vital part of our world that demands to be protected. Every painstaking detail Proulx embeds serves as a suggestion to fully appreciate the world around us, akin to how the indigenous people do in the novel, an understanding that is cruelly ignored by the foreigners. It is a warning that we should not continue to neglect what we can see.

The generations of the Duquet and Sel families are all inextricably linked by the trees but their false ideal of the boundless forests, and their naiveté of how to safeguard for the future, is a message which Proulx hammers home throughout. The successive and inevitable ruin of the forests in such monumental proportions throughout the novel provides the evidence that we all have a part to play in conservation era by era, with the areas that Proulx brings to life - such as the woodlands of North America - as proof of the beauty of our planet. Barkskins provides a revelatory survey of how we came to be in this situation. Its urgent ecological message is one that has been explored before, but not quite to this scale in fiction, or perhaps anywhere else.

Reviewed by Anastasia Broadbridge

Published online: 7 November 2017 https://doi.org/10.1038/s41477-017-0056-y 